\title{
EDUCATION AND TRAINING
}

\section{Positive Regard in Clinical Supervision: Trainee Perspectives}

\author{
Emily Carl, $M A$
}

The University of Texas at Austin

Natasha H. Bailen, MA

Washington University in St. Louis

The supervision relationship is multifaceted. Watkins (2011) wrote, "Is supervision teaching? Is supervision therapy? Is supervision consultation? Is it some blend of the three?" Although the primary objectives of supervision are to foster professional growth, monitor the quality of professional services, and serve as a gatekeeper for the profession (Bernard \& Goodyear, 2014), the similarities to a therapeutic relationship cannot be overlooked. Both relationships rely on a strong working alliance, are intended to promote personal development through guided discovery and problem-solving, and ideally adhere to the major principles of the therapeutic orientation (Newman \& Kaplan, 2016; Milne, 2006). Furthermore, the supervision relationship can be used as a platform for modeling therapeutic skills. In an interview with the APA (Tracey, 2006), Dr. Judith Beck said that during supervision she will "directly model what [she] would like to see [trainees] do in a therapy session" in order to demonstrate a collaborative relationship.

One well-established element of effective psychotherapy is unconditional positive regard (Rogers, 1957a; Farber \& Doolin, 2011; Keijsers, Schaap, \& Hoogduin, 2000). Rogers wrote that when a therapist is experiencing unconditional positive regard, he feels warmly toward the client's weaknesses and problems as well as the client's potential (Rogers, 1957a). Rogers also believed that clinical supervisors should model unconditional positive regard toward trainees during supervision (1957b).

Evidence supports this assertion. The trainee-reported strength of the supervisory alliance has been found to be associated with client-reported strength of the therapy relationship, as well as trainee adherence to the intended treatment model (Patton \& Kivlighan, 1997). There is evidence that components of positive regard, including warmth, empathy, and genuineness, are essential to the effectiveness of didactic training (e.g., Carifio \& Hess, 1987; Lambert, 1980). Trainees report that positive experiences in supervision frequently involve support, empathy, respect, and an attitude of non-judgment on the part of the supervisor (Kennard, Stewart, \& Gluck, 1987; Watkins, 1995; Worthen \& McNeill, 1996). Lastly, therapists trained by supervisors who scored highly on dimensions including empathy, respect, and genuineness tended to exhibit the greatest gains in these dimensions from before to after training (Carkhuff \& Berenson, 1967; Pierce, Carkhuff, \& Berenson, 1967; Truax \& Carkhuff, 1967). 
Conversely, a survey of doctoral students or recent graduates found that clinical supervision that emphasized negative or critical styles (e.g., "criticized my performance in a demeaning and personal way") was associated with a weaker experience of the bond in the alliance (Ladany, Mori, \& Mehr, 2017). Supervisory alliances perceived by trainees as unsatisfactory or weak have been associated with trainee stress, exhaustion, and burnout (Watkins, 2014).

It is apparent that positive regard is crucial in the clinical supervision relationship, but how does this practically play out? A trainee might approach supervision sessions wondering what to expect from a supervisor: Will the supervisor observe my negative or positive qualities that will affect my clinical work? Will the supervisor see me and my work the way I see myself, or will I be blindsided by feedback? Will the supervisor assume the best of me and my intentions when there is incomplete information? We present three exchanges between supervisors and trainees from our pre-doctoral, pre-practicum and practicum training in which positive regard or the lack of it was a turning point in the relationship and training experience.

\section{Case Illustrations}

Setting the tone: Early in one of these authors' experience with a new supervisor, the supervisor ended a group supervision session by reflecting a unique strength she saw in each of the beginning counselors. What she said to me seemed accurate and felt meaningful. Having her notice and appreciate a strength in me helped me to feel that even in the event of a mistake or negative feedback in our future work, she would likely still perceive some positive qualities. Moving forward, I felt less anxious in our meetings and I was more willing to be candid with her.

The initial meeting with the supervisor sets the tone for the supervisory relationship (Magnuson, Norem, \& Wilcoxon, 2002). In this case, the tone was set for a supportive relationship. In an interview with APA, Dr. Stoltenberg, a Professor in Educational Psychology and Director of Training at the University of Oklahoma, endorsed the use of "supportive and facilitative interventions, in which supervisors provide support and encourage the development of the trainee through praise and attentive listening." (Tracey, 2006).

Furthermore, the reflection of strengths within a counseling relationship has been suggested as a way to develop them. In their chapter "Toward a positive psychotherapy: Focus on human strength," Gelso and Woodhouse (2003, p.182) suggest that therapists can comment on strengths that are not yet fully developed in order to encourage them: "Therapists can react to the nascent strengths in a way that appropriately reflects and magnifies them." Thus, this action by this supervisor may have served two very valuable purposes early in the supervisees' training: to bolster the supervision alliance, and to support the development of strengths.

Validating and reinforcing difficult disclosures: One of these authors suspected that a client had negatively interpreted and possibly taken offense to a suggestion. I was nervous to tell my supervisor, fearing that posing the suggestion to the client had been a mistake. My supervisor first thanked me for raising this issue, and provided validation that therapists' words can often be misinterpreted. She then asked what made me feel badly about the interaction, and we roleplayed addressing the miscommunication with the client. Finally, she asked me to consider how I might react differently if a similar situation arose next time. I felt grateful for the room to explore 
what had occurred, and subsequently, I felt better able to disclose situations and decisions that made me feel vulnerable as a clinician.

It is widely acknowledged that supervision can be anxiety-provoking for trainees, as supervision entails performance evaluation and there is a power dynamic inherent in the relationship. However, Milne (2006, p. 215) pointed out that the supervision process mirrors the therapy process in that both involve a "shared emphasis on a problem-solving approach, founded on a working alliance." Trainee anxieties can be alleviated by supervisors' conveyance of trust and positive regard (Newman \& Kaplan, 2016; Talen \& Schindler, 1994); this then serves to strengthen the working alliance. In the above illustration, positive regard was expressed and the alliance was strengthened by the normalization of trainee difficulties and reinforcement of a difficult disclosure (Newman \& Kaplan, 2016).

The establishment of a safe, nonjudgmental environment allowed for the focus of supervision to shift to problem-solving. The supervisor's positive regard relieved the trainee's anxiety about how what occurred might reflect on her, and allowed for a productive exploration of how ruptures in the therapeutic relationship could be repaired and how to do differently next time.

A breach in positive regard: While reviewing a videotaped session, one of these authors was once told by a supervisor that they seemed "unprepared" during a meeting with a client. She then asked me if I had done anything to prepare for the session. Because she had asked if I had prepared at all, it seemed to me she thought I must not invested. In fact, I had spent a great deal of time preparing. I thought my good intentions and level of hard work were unnoticed, and I felt misunderstood. I never mentioned how it had impacted me, but I found myself feeling more guarded and defensive in our supervision sessions afterward.

This case illustrates an instance when a trainee felt a breach in perceived positive regard from her supervisor. While assessing for the level of preparation was appropriate in this professional relationship, the manner and tone in which it was asked led the trainee to feel defensive about her work. The result was a weakening of the supervision alliance and a degree of withdrawal from the process by the trainee.

There is evidence that it is common for a trainee's perception of a negative exchange to go unnoticed while having far-reaching consequences. In interviews with psychotherapy trainees about counterproductive events in supervision, Gray, Ladany, Walker, and Ancis (2001) found that most trainees did not believe that their supervisors were aware of the impact of the event, and most did not disclose the event to their supervisors. Meanwhile, all trainees stated that the event weakened the relationship, led to a change in their approach to their supervisors, and most even believed this negatively affected their work with their clients. Thus, exchanges that might be subtle enough to go unnoticed by the supervisor can still be very damaging to the work. In the illustrated case, a subtle conveyance of negative assumptions about the trainee weakened the supervision alliance.

\section{Discussion}

Several important lessons can be drawn from these exchanges. First, supervisors should work to establish a supportive tone early in the relationship. Having this in place early will create an 
environment in which trainees are comfortable disclosing disagreement, confusion, or difficult situations with clients. Similarly, whenever possible, supervisors should take care to convey positive regard during instances of evaluation or ambiguity. Given that the supervisory relationship is inherently evaluative and critical feedback is necessary (Newman \& Kaplan, 2006), positive regard will not look the same in supervision relationships as it does in therapeutic ones. However, positive regard or the lack of it still has an effect on this relationship; the second case illustrates that in the presence of ambiguous information, assuming the best of the trainee's work and intentions while delivering feedback might avoid a rupture and facilitate problemsolving.

Next, trainees can be mindful of their reactions when they feel the absence of positive regard. Mehr, Ladany and Caskie (2010) found that trainees who rated their working alliance with their supervisor more highly reported more willingness to disclose, and that higher trainee anxiety was related to less willingness to disclose. Likewise, Yourman (2003) reviewed four cases that illustrated that ruptures in the supervisory relationship led to feelings of shame for trainees and inhibited disclosure. Therefore, it is important for trainees to note how they might be influenced by their perception of their supervisor's regard toward them, especially in terms of withholding information. Of note, positive regard does not, and should not, preclude constructive feedback and problem-solving. In fact, positive regard at its best facilitates difficult conversations: if supervisees are assured that their supervisors hold them in positive regard, they can disclose more easily, because they can trust that advice and feedback are well-intentioned.

As Kottler and Hazler (1997) remarked, supervision operates within the tension of a working alliance in which supervisors must juggle multiple responsibilities, including imparting new skills and techniques to trainees, ensuring client welfare, and setting the bar for competence in the profession. However, despite the professional nature to this relationship, we have demonstrated in the preceding examples that this is also a relationship in which positive regard is appropriate and critical. The presence or absence of positive regard has the potential to alter the trajectory of a supervision alliance, the trainees' professional development, and ultimately, the quality of the services delivered to the client. Illustrations from our clinical training demonstrate the practical, day-to-day ways that this crucial component of effective supervision plays out. 


\section{References}

Bernard, J. M., \& Goodyear, R. K. (2014). Fundamentals of clinical supervision (5th ed.). Upper Saddle River, NJ: Merrill.

Carifio, M. S., \& Hess, A. K. (1987). Who is the ideal supervisor?. Professional Psychology: Research and Practice, 18(3), 244

Carkhuff, R., \& Berenson, B. (1967). Beyond counseling and theory. New York, NY: Holt, Rinehart \& Winston.

Farber, B. A., \& Doolin, E. M. (2011). Positive regard. Psychotherapy, 48(1), 58.

Gray, L. A., Ladany, N., Walker, J. A., \& Ancis, J. R. (2001). Psychotherapy trainees' experience of counterproductive events in supervision. Journal of Counseling Psychology, 48(4), 371.

Gelso, C. J., \& Woodhouse, S. (2003). Toward a positive psychotherapy: Focus on human strength. In W. B. Walsh, Counseling psychology and optimal human functioning (pp. 171-197). New York, NY: Routledge.

Keijsers, G. P. J., Schaap, C. P. D. R., \& Hoogduin, C. A. L. (2000). The impact of interpersonal patient and therapist behavior on outcome in cognitive-behavior therapy: A review of empirical studies. Behavior Modification, 24(2), 264-297.

Kennard, B. D., Stewart, S. M., \& Gluck, M. R. (1987). The supervision relationship: Variables contributing to positive versus negative experiences. Professional Psychology: Research and Practice, 18(2), 172.

Kottler, J. A., \& Hazler, R. J. (1997). What you never learned in graduate school: A survival guide for therapists. New York, NY: Norton.

Ladany, N., Mori, Y., \& Mehr, K. E. (2013). Effective and ineffective supervision. The Counseling Psychologist, 4l(1), 28-47.

Lambert, M. J. (1980). Research and the supervisory process. In A. K. Hess (Ed.), Psychotherapy supervision: Theory, research, and practice (pp. 423-452). New York, NY: Wiley.

Magnuson, S., Norem, K., \& Wilcoxon, S. A. (2002). Clinical supervision for licensure: A consumer's guide. The Journal of Humanistic Counseling, Education and Development, $41(1), 52-60$.

Mehr, K. E., Ladany, N., \& Caskie, G. I. (2010). Trainee nondisclosure in supervision: What are they not telling you?. Counselling and Psychotherapy Research, 10(2), 103-113. 
Milne, D. (2006). Developing clinical supervision research through reasoned analogies with therapy. Clinical Psychology \& Psychotherapy: An International Journal of Theory \& Practice, 13(3), 215-222.

Newman, C. F., \& Kaplan, D. A. (2016). Supervision essentials for cognitive-behavioral therapy. Washington, DC: American Psychological Association.

Patton, M. J., \& Kivlighan, D. M. J. (1997). Relevance of the supervisory alliance to the counseling alliance and to treatment adherence in counselor training. Journal of Counseling Psychology, 44, 108-111.

Pierce, R., Carkhuff, R. R., \& Berenson, B. G. (1967). The differential effects of high and low functioning counselors upon counselors-in-training. Journal of Clinical Psychology, 23(2), 212-215.

Rogers, C. R. (1957a). The necessary and sufficient conditions of therapeutic personality change. Journal of Consulting Psychology, 21(2), 95.

Rogers, C. R. (1957b). Training individuals to engage in the therapeutic process. In C. R.Strother (Ed.), Psychology and mental health (pp. 76-92). Washington, DC: American Psychological Association.

Talen, M. R., \& Schindler, N. J. (1994). Goal-directed supervision plans: A model for trainee supervision and evaluation. The Clinical Supervisor, 11(2), 77-88.

Tracey, M. D. (2006, March). More effective supervision: Clinical supervision informed by research and theory can help trainees excel. Retrieved from: http://www.apa.org/monitor/mar06/supervision.aspx

Truax, C., \& Carkhuff, R. (1967). Toward effective counseling and psychotherapy: Training and practice. Chicago: Aldine.

Watkins, C. E., Jr. (1995). Psychotherapy supervisor and supervisee: Developmental models and research nine years later. Clinical Psychology Review, 15(7), 647-680.

Watkins, C. E., Jr. (2010). Psychoanalytic constructs in psychotherapy supervision. American Journal of Psychotherapy, 64(4), 393-416.

Watkins, C. E. (2011). Psychotherapy supervision since 1909: Some friendly observations about its first century. Journal of Contemporary Psychotherapy, 41(2), 57-67.

Watkins, C. E. (2014). The supervisory alliance as quintessential integrative variable. Journal of Contemporary Psychotherapy, 44(3), 151-161.

Worthen, V., \& McNeill, B. W. (1996). A phenomenological investigation of "good" supervision events. Journal of Counseling Psychology, 43(1), 25. 
Yourman, D. B. (2003). Trainee disclosure in psychotherapy supervision: The impact of shame. Journal of Clinical Psychology, 59(5), 601-609. 